\title{
Buscando las raíces de la Antropología: Contribución para una reconstrucción de la génesis de la Antropología en el período jenense de Hegel
}

\author{
FEDERICO SANGUINETTI \\ Universidad de Pisa
}

La Antropología representa, como es sabido, la última de las ciencias filosóficas que obtiene una colocación autónoma al interior de la Enciclopedia hegeliana: su exposición es anunciada oficialmente sólo en el tercer libro de la Ciencia de la Lógica, y es tematizada en la primera edición de la Enciclopedia en 1817. Partiendo del dato de su tardía tematización, el objetivo de esta contribución es individuar un itinerario que justifique el recorrido genético de la definición sistemática de la Antropología. Este análisis, que se limitará al periodo jenense, tendrá como punto de partida un conjunto de problemas especulativos y sistemáticos que ahondan sus raíces en los primeros intentos hegelianos de estructurar su propio pensamiento en un sistema que supere las unilateralidades del realismo y del idealismo trascendental.

La Antropología, en efecto, tiene como objeto la cesura problemática que une, y al mismo tiempo separa, las esferas de la naturaleza y del espíritu, cesura que contextualmente coincide con el lugar sistemático de una filosofía de la individualidad humana y de su relación con la objetividad. Es en el periodo pre-fenomenológico cuando, partiendo de la búsqueda de un principio especulativo del filosofar, viene paralelamente formándose una filosofía de la subjetividad que se haga cargo de la mediación entre aquellos dos mundos y de la perspectiva especulativa del sistema mismo.

A partir del Systemsfragment de $1800^{1}$, la posición de naturaleza y espíri-

1 Ese fragmento no pertenece propiamente a la producción jenense de Hegel, habiendo sido terminado en Frankfurt (14 Septiembre 1800) algunos días antes de la famosa carta a Schelling del 2 de Noviembre 1800, en la que Hegel anuncia su intención de "arriesgar[se] en el zumbido literario de Jena". 
tu, como mundos en cuyo interior se sitúa la individualidad humana, se funde con la necesidad de un principio especulativo del filosofar que caracterice las relaciones entre esas dos grandes esferas. Si la naturaleza se define aquí como el mundo puesto por la reflexión intelectual y el espíritu como el mundo de la razón unificante, tanto las dos esferas de la realidad como los respectivos principios especulativos que las gobiernan no se compenetran armónicamente, sino que quedan irremediablemente opuestos. La ausencia de una mediación entre intelecto reflexionante y razón inmediatamente unificante se refleja en un salto de la realidad natural a la divina que relega el individuo humano a una posición intermedia inconciliada y conflictual.

En la Differenzschrift, Hegel critica el principio teorético de aquella escisión en las modalidades especulativas del idealismo trascendental, dicho principio origina como su resultado una visión tergiversada de la realidad humana. La mezcla de reflexión intelectual e intuición trascendental, inserida en la conciencia como punto de partida unilateralmente subjetivo del filosofar, conlleva por un lado la devaluación radical de la esfera de la realidad natural; por el otro el subyugamiento de la individualidad humana en una realidad política que se presenta como jaula exterior y limitación de la libertad del individuo.

En el marco de la colaboracióń con Schelling, Hegel reconoce como primer paso hacia una solución de las aporías teóricas y sistemáticas del idealismo trascendental la estructuración de una filosofía de la naturaleza que se constituya como autónoma con respecto a la filosofía del espíritu y de una racionalidad que se coloque en el punto medio de esta oposición; al mismo tiempo, Hegel se dedica, desde su llegada a Jena, a una elaboración autónoma de una lógica metafísica, separada pero en estrecha conexión con la constitución concreta de la subjetividad, que haga emerger la razón especulativa de la superación de las formas finitas de la reflexión, en las que quedan atrapadas las filosofías ingenuamente realistas o idealistas.

Desde su primer curso sobre Lógica y Metafísica (1801/02), Hegel relaciona la problemática del principio especulativo del filosofar como resultado de la superación de las determinaciones reflexivas, sean ellas consideradas en un horizonte realista o idealista, con la exigencia de una formulación nueva de la filosofía de la subjetividad, lugar en el que se condensan las contradicciones de tales enfoques.

La subjetividad individual como unión de alma y cuerpo representa, en efecto, el lugar de intersección de las esferas de la naturaleza y del espíritu. Por consiguiente, una comprensión correcta de la individualidad humana y de las modalidades de su filosofar define paralelamente la correcta tematización de los dos mundos en cuyo interior ella se inserta y, al mismo tiempo, delinea la colocación sistemática de aquellos.

Sin embargo, la génesis de una tematización sistemática de una filosofía de 
la subjetividad que se haga cargo de estas premisas no se revela, en absoluto, simple y linear.

En el Naturrechtsaufsatz, se constata un cambio de enfoque estructural. Hegel se aleja de una perspectiva sistemática inspirada en un paralelismo de matriz schellinguiana, proponiendo una subordinación de lo natural respecto a la realidad espiritual, la cual se define en su forma realizada como sustancia ética.

De esa forma, el lugar sistemático de una filosofía de la subjetividad se define progresivamente, en el curso de los esbozos sistemáticos hegelianos, como punto de encuentro de dos vectores: el primero se mueve desde la constitución del mundo natural como proceso de concretización y realización en la realidad espiritual, a partir del dato de la otredad de la naturaleza respecto al espíritu; el segundo se realiza como recorrido de abstracción progresiva que parte de la sustancia ética como espíritu efectivamente realizado.

En el primer Systemsentwurf (1803/04), Hegel realiza una primera exposición sistemática de naturaleza y espíritu como esferas asimétricamente y axiológicamente ordenadas de la manifestación del absoluto; sin embargo, el transito de la naturaleza al espíritu resulta en un primer momento todavía insuficientemente mediado. Hegel aparece en primer lugar deudor de una perspectiva schellinguiana de un dualismo paralelo de naturaleza y espíritu ético como manifestaciones del absoluto. Por otra parte demuestra estar todavía atado a la perspectiva de la conciencia como primera manifestación de lo espiritual, aunque ésta se presente sólo como abstracción de la sustancia ética. Por un lado la naturaleza no está todavía determinada lógicamente como el lugar de la otredad del espíritu, por el otro es la conciencia la estructura responsable de desarrollar la tarea de la mediación entre naturaleza y espíritu, sin embargo la desarrolla según su peculiar perspectiva de la escisión.

A pesar de que Hegel conciba su propia tematización de la subjetividad individual como superación de las aporías del idealismo trascendental y del realismo ${ }^{2}$, este primer intento de mediación entre objetividad natural y subjetividad singular se demuestra todavía incompleto. En ese contexto, de hecho, los grados subordinados de la conciencia se consideran todavía únicamente al interior de la estructura escindida de aquella, concebida como "[d]ie erste Form der Existenz des Geistes" 3 . Falta todavía, por lo tanto, una estructura específica que, por medio de una organización conceptual de estos materiales, constituya el presupuesto de la conciencia, mientras la sustancia racional de la mediación es todavía reconocida sólo en la realizada concretización ética del espíritu, es decir, por encima y más allá de la abstracción que caracteriza la 
conciencia y el individuo humano.

Lo que se hace necesario, por consiguiente, es una deducción del punto de vista de la conciencia, de manera que ésta no represente el substrato de la mediación, sino que a su vez sea mediada y deducida por un proceso inferior que dé cuenta de su constitución y que constituya su correlato objetivo.

El tema de la deducción de la conciencia, en este caso como yo teorético, es discutido por Hegel, antes que a nivel de filosofía real, a nivel lógico-metafísico en el manuscrito sobre Logik, Metaphysik und Naturphilosophie 1804/1805. Se trata del itinerario que el principio del fundamento racional, resultado de la Aufhebung de las formas lógicas de la reflexión, debe de cumplir al interior de la metafísica de la objetividad, para lograr el horizonte de su propia realización al interior de la metafísica de la subjetividad, cuyo primer momento coincide con el yo teorético mismo, o conciencia. De esta manera la temática del principio especulativo del filosofar que no quede atrapado en las determinaciones de la reflexión y la temática de la deducción del punto de vista de la conciencia a partir de un horizonte objetivo se entrelazan indisolublemente.

Hegel, en efecto, deduce aquí el punto de vista del yo en primera persona a través del itinerario de realización del principio del fundamento en la metafísica de la objetividad, construida alrededor del la noción de alma ${ }^{4}$. El concepto de alma coincide con la primera, imperfecta realización metafísica del principio del fundamento en su forma substancial y objetiva; sin embargo, el alma como sustancia objetiva se revela como un conocer en sí, es decir, presenta internamente la actividad de la reflexión y es ya una subjetividad in nuce ${ }^{5}$.

Así Hegel, haciendo del yo una reflexión interior en sí del movimiento precedente y objetivo, supera un saber que se contrapone al objeto sólo frontalmente, dado que el objeto es ya en sí mismo algo mediado y reflexionado.

De hecho, la perspectiva de la escisión que caracteriza el yo se inserta en el contexto autoreferencial que tiene como extremos la "sujeto-objetividad objetiva" del alma y la "sujeto-objetividad absoluta" del espíritu absoluto: ahora, el objeto que se contrapone al yo no es ya algo absolutamente otro, sino coincide con el entero desarrollo precedente del yo, su presupuesto como "sujeto-objeto objetivo", del que el yo toma nuevamente distancia ${ }^{6}$.

Este decisivo paso a nivel lógico-teorético conlleva consecuencias impor-

4 En un sentido específico, la noción de alma indica sólo el primer momento de la metafísica de la objetividad, pero la metafísica de la objetividad representa en su totalidad el desarrollo del concepto de alma, el cual se demuestra pervasivo con respeto a la entera sección.

5 Cfr. Hegel, G.W.F., GW 7, p. 140: “[...] die Substanz ist vielmehr, Subjekt, in welchem die Bestimmtheit nicht als eine wirkliche, sondern als eine besondere, d.h. ihrer Beziehung auf ihre entgegengesetzte entnommen ist".

6 Cfr. Hegel, G.W.F., GW 7, p. 161: "Dem Ich ist die Selbsterhaltung der Seele, selbst der Gegenstand". 
tantes a nivel de filosofía real. De hecho, se expresa aquí la idea central que caracterizará los sucesivos desarrollos de tematización de la transición de la naturaleza al espíritu, es decir, la estructura de un saber autoreferencial que se realiza desde un fundamento objetivo y natural para llegar a la subjetividad del yo conciencial como reflexión en sí y asimilación de tal recorrido.

El impacto de este enfoque metafísico más maduro se hace inmediatamente evidente en el sucesivo Systemsentwurf (1805/06). En este esbozo, en efecto, se consolida la idea de una estructura de un saber que se realiza a partir de los grados de su pasividad y exterioridad a sí mismo hasta a su propia actualización como intrínseca unidad consigo.

En este nuevo contexto, por un lado el itinerario de la naturaleza, desde sus manifestaciones más abstractas hasta su máxima realización en la filosofía de lo orgánico, se especifica en el sentido de un proceso de Verselbung, a saber, de subjetivización conceptual, que encuentra su inmanente realización en el espíritu como autoreferencialidad concreta. De este modo, se acentúa la conexión entre la idea de una teleología objetiva como motor del proceso natural con la noción auténtica de subjetividad, no concebida unilateralmente como yo personal, sino como inmanencia de la propia autoreferencia. Por otro lado, el espíritu se configura como Sí-Mismo (Selbst) realizado, estructura autoreferencial efectiva, no unilateralmente subjetivo-personal a la manera de un yo, sino a la tercera persona, estructura que se realiza concretamente sólo en lo ético.

Aunque en este esbozo la exposición de la subjetividad individual se estructura según un enfoque que se aproxima más a la psicología del sistema maduro $^{7}$, lo que es interesante notar es que la transición de la naturaleza al espíritu no se produce en la forma de la conciencia, sino que se introduce la noción de un Sí-Mismo subconciencial y subpersonal que se hace cargo, en su inmediata conexión con la objetividad natural, de la deducción de la perspectiva escindida de la conciencia que contrapone sujeto y objeto.

Es a través del desplazamiento de la razón especulativa desde la esfera absoluta de lo ético a la singularidad racional y de la separación de la región subconciencial, como base substancial de los siguientes desarrollos del espíritu, que se delinea la tripartición madura del espíritu subjetivo y se desvalora el punto de vista teorético y sistemático de la conciencia, la cual obtendrá una peculiar exposición en la Fenomenología del Espíritu de 1807.

De tal manera, la exigencia de la tematización de una región sistemática que medie la relación entre conciencia y naturaleza, y la de una base teorética

7 Es necesario subrayar, de nuevo, como la filosofía de la subjetividad no exhibe todavía una propia autonomía sistemática y se caracteriza todavía sólo como abstracción de la sustancia ética. 
sujeto-objetiva e indiferenciada de la realización de la perspectiva auténticamente racional del individuo, se entrelazan recíprocamente ${ }^{8}$.

La Antropología como primer momento de la filosofía del espíritu subjetivo se injertará en el espacio sistemático que viene creándose entre naturaleza y conciencia, y representará en cierto sentido el correlato real-filosófico de la deducción metafísica del yo teorético. No es casual que Hegel estructure la Antropología alrededor de la noción de alma ${ }^{9}$, noción que realizará la identificación entre la sustancia dinámica, que funda la transición desde el horizonte objetivo y natural al horizonte auténticamente subjetivo y espiritual, y la estructura del Sí-Mismo subconciencial como subjetividad máximamente formal y natural.

Aunque en Jena Hegel no da todavía ese paso teórico, sin embargo prepara el terreno de la futura tematización antropológica de la subjetividad formal y de su íntima conexión con la noción de sustancia como identidad de subjetividad y objetividad. Tal preludio se puede entrever, en el contexto del Systemsentwurf (1805/06), en la homología del Sí-Mismo subconciencial, estructura específica de la subjetividad más formal, con la substancialidad actualizada del Sí-Mismo sobreconciencial, en el cual sujeto y objeto se identifican efectivamente.

Así Hegel pone las bases para una futura concepción del sistema en el que la estructura autoreferencial a la tercera persona, no a la primera, del espíritu como Sí-Mismo, no indica sólo la mediación racional de las oposiciones de la conciencia como espíritu objetivo y ético superior respeto a aquella. Más bien el espíritu como Sí-Mismo viene constituyéndose como parte integrante de una estructura subconciencial y no todavía personal, que se presenta, en cuanto subjetividad máximamente formal, como mediación, fundamento y base substancial objetiva de la transición de la naturaleza al espíritu como conciencia.

La conciencia como yo no representa ya el primer momento, al mismo tiempo asimilador y negativo con respeto a la naturaleza. Ella se caracteriza, de aquí en adelante, por su propia intrínseca negatividad tanto respecto a su base substancial e inconsciente, la que se hace cargo de la tarea de asimilación de la naturaleza al interior del horizonte espiritual, como respecto al Sí-Mismo realizado del espíritu ético.

Ya en el curso del periodo jenense, la unión del problema de una deducción lógica de la conciencia a partir de una indiferenciada unidad substancial, con el problema de una deducción real-filosófica del yo a partir de su identidad con

8 Tal base indifrerenciada no debe, sin embargo, ser concebida en terminos schellinguianos como punto medio indiferenciado de naturaleza y espíritu, sino como subjeto-objetividad ya dinamizada y activada por el movimiento subjetivo de reflexión en sí misma.

9 Cfr. Chitereghin, F., L'Antropologia come scienza filosofica, en Filosofia e scienze filosofiche nell' "Enciclopedia" hegeliana del 1817, a cura di F. Chiereghin, Trento, Quaderni di Verifiche 6, 1995, pp. 429-454. 
la naturaleza, está explícitamente testimoniada por la contextual repetición de la metáfora que opone la noche a la luz del día.

En la Differenzschrift Hegel escribía:

"Das Absolute ist die Nacht, und das Licht ist jünger als sie, und der Unterschied beider, sowie das Heraustreten des Lichts aus der Nacht eine absolute Differenz, - das Nichts das Erste, woraus alles Sein, alle Mannigfaltigkeit des Endlichen hervorgegangen ist" 10 .

En el Systemsentwurf(1805/06), análogamente, el Sí-Mismo subconciencial se define como la "Nacht der Aufbewahrung"11, "das Innere der Natur"12, síntesis y superación del objeto y de la naturaleza misma en el espíritu, a partir del cual emergerán las diferencias que definen la estructura de la conciencia despierta ${ }^{13}$.

Así, en el contexto del sistema maduro, es en la Antropología como ciencia del espíritu en los grados de su oscuridad ${ }^{14}$ que se tematiza la transición de la noche de la sustancia a la luz del yo, pasaje que está prefigurado como transición del sueño a la vigilia. Esta transición asume un significado profundamente especulativo más allá del mero análisis de los fenómenos psíquicos de la subjetividad formal del individuo, los que representan, de hecho, el recorrido de génesis del relámpago (Blitz) de la subjetividad a partir de la oscuridad substancial del alma.

Por consiguiente, es al interior de la tematización madura del concepto de alma en la Antropología que la exigencia de una base sujeto-objetiva del espíritu - emergida en la naturaleza aunque ya en sí activa y dinámica respeto a aquella - y la exigencia de una deducción del punto de vista conciencial a partir de los grados inferiores, en función anti-realista y anti-idealista, encuentran una solución común. El alma es definida, en efecto, como

"die Substanz, die absolute Grundlage aller Besonderung und Vereinzelung des Geistes" $"$;

y al mismo tiempo ella se estructura como Sí-Mismo, subjetividad formal que emerge de la naturalidad, y para la cual la exterioridad y la materialidad han perdido toda relevancia.

10 Hegel, G.W.F., GW 4, p. 16.

11 Hegel, G.W.F., GW 8, p. 186.

12 HegEL, G.W.F., GW 8, p. 187.

13 Con respeto a este tema cfr. también Hegel, G.W.F., GW 7, p. 154: "Das höchste Wesen hat die Welt geschaffen, die für dasselbe von ätherheller Durchsichtigkeit und Klarheit ist; aber diese ist für sich selbst finster."

14 Hegel, G.W.F., GW 12, p. 197.

15 Hegel, G.W.F., GW 20, § 389, p. 288. 
Ya en este ínfimo nivel del espíritu, Hegel reconoce como superados los enfoques unilateralmente realistas o idealistas en la tematización de la relación entre espíritu y naturaleza: si estos enfoques se revelan, en último análisis, vinculados a un filosofar a través de determinaciones reflexivas, en el alma, en virtud de su idealidad, se cumple a nivel realfilosofico aquella confutación del determinar reflexionante, que ya había sido realizada a nivel lógico ${ }^{16}$. La idealidad, es decir la Aufhebung de la otredad en una actividad autoreferencial, es la característica esencial del espíritu en toda su manifestación, y es en virtud de esta pervasividad de la idealidad del espíritu que el alma se puede presentar como sustancia en potencia de toda determinación espiritual ${ }^{17}$.

Como he intentado mostrar, tal posición tiene como presupuesto genéticosistemático la inserción del Sí-Mismo subconciencial, como análogo del Simismo absoluto.

En conclusión, desde el periodo jenense, Hegel demuestra haber comprendido que la condición imprescindible para una racionalidad que se presente como auténtica identidad de sujeto y objeto es una deducción del punto de vista escindido de la conciencia a partir no sólo de una sujeto-objetividad absoluta y superior, sino de una estructura que se revela al mismo tiempo máximamente objetiva y abstractamente subjetiva. Tal estructura realiza de esta manera la conexión del horizonte espiritual con el horizonte natural según una unidad dinámica dirigida hacia el desarrollo de la subjetividad a partir de la objetividad. Este paso se revela fundamental en el proyecto de la estructuración definitiva de una filosofía de la subjetividad que se haga cargo de las exigencias de un idealismo auténticamente objetivo, o más bien absoluto, más allá de las unilateralidades de la filosofía trascendental y del realismo ingenuo.

16 Cfr. Hegel, G.W.F., Enzyklopädie der philosophischen Wissenschaften im Grundrisse (1830), Frankfurt am Main, Suhrkamp, 1970, § 389, Zusatz, p. 47: “Über die ganze bloß reflektierende Betrachtungsweise erhebt uns schon die spekulative Logik, indem sie zeigt, daß alle jene auf die Seele angewandten Bestimmungen - wie Ding, Einfachheit, Unteilbarkeit, Eins - in ihrer abstrakten Auffassung nicht ein Wahres sind, sondern in ihr Gengenteil umschlagen. Die Philosophie des Geistes aber setzt diesen Beweis der Unwahrheit solcher Verstandeskategorien dadurch fort, daß sie dartut, wie durch die Idealität des Geistes alle festen Bestimmungen in demselben aufgehoben sind."

17 Hegel define el alma como "der passive Nus des Aristoteles, welcher der Möglichkeit nach Alles ist.” [HeGEL, G.W.F., GW 20, § 389, p. 388] 